\title{
Creating open access books: a partnership between a university library and a research centre
}

\author{
Janet Aucock \\ University of St Andrews
}

This case study describes a partnership that has developed at the University of St Andrews between a particular research centre, the St Andrews Centre for French History and Culture ${ }^{1}$ and the University Library. The product of this partnership since 2010 is a unique series of "midigraphs", which are shorter monographs and collaborative volumes of 25,000-50,000 words, published as the St Andrews Studies in French History and Culture. Six ebooks ${ }^{2}$ have already been produced, and future publications are planned with a regular publication schedule. The library and the editor-in-chief of the ebook series have a close working relationship which enables this series to be made available as open access ebooks in the university repository, Research@ StAndrews:FullText. The books are also published in paperback with a limited free print run (see Figure 1). Titles are rigorously peer-reviewed and, in keeping with the mission of the centre to "enhance public understanding of the Francophone world", the publications are free at the point of delivery and

1 Centre website http://www.st-andrews.ac.uk/history/frenchcentre/publications.shtml

2 http://research-repository.st-andrews.ac.uk/handle/10023/846/browse?type= title\&submit_browse=Title

\section{How to cite this book chapter:}

Aucock, J. 2014. Creating open access books: a partnership between a university library and a research centre. In: Woodward, H. (ed.) Ebooks in Education: Realising the Vision. Pp. 91-103. London: Ubiquity Press. DOI: http://dx.doi.org/10.5334/bal.j 


\section{Caste, Class and Profession in Old Regime France: the French Army and the Ségur Reform of 1781}

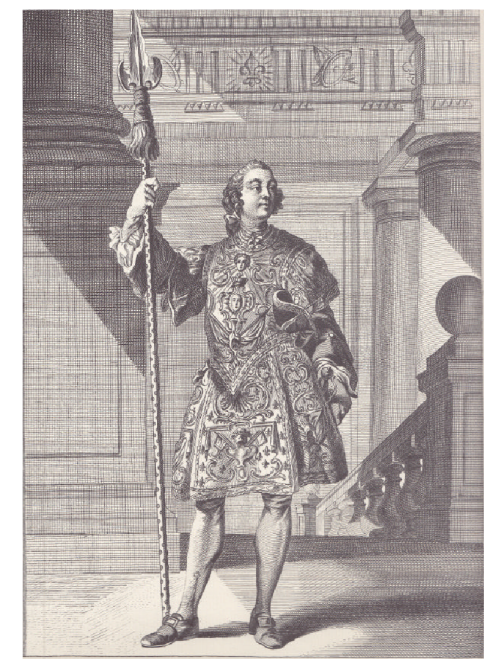

\section{David D. Bien}

with Jay M. Smith and Rafe Blaufarb

St Andrews Studies in French History and Culture

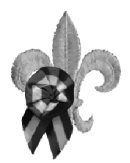

Figure 1: BIEN, D. D., SMITH, J. M., \& BLAUFARB, R. (2010). Caste, class and profession in old regime France the French: army and the Ségur reform of 1781. Image from the title page reproduced by kind permission of the owner. 
come with no charge for consultation, downloading, printing or circulation, either for private use or for educational purposes.

The development of this ebook series is of particular interest because of its short study format, its humanities disciplinary base, and its use of the repository for scholarly communication, discovery and archiving. However, this partnership was created organically and was never in fact a planned project. Rather, it was the result of the enthusiasm of the research centre for the development of a new platform and mechanism for communication of scholarly research, combined with the availability of open-access services within the university library. The collaboration began as a result of seeds sown in conversation between individual library staff and the research centre, and converged with the realisation that existing library services could be used to provide the institutional repository as a platform for open-access ebooks.

Each ebook in the series carries multiple acknowledgements on its title page verso to mark the collaboration of the St Andrews Centre for French History and Culture with its publishing partners, and it is satisfying to see that one of the partners listed is the University of St Andrews Library. This case study describes how that partnership came about and considers the perspective of the research centre, editor, library and authors, as well as exploring some aspects of the value, usage and visibility of the open-access ebooks. In conclusion, we look forward to the future of the series and its potential impact on publishing initiatives within the wider institution.

\section{The research centre and editorial perspective}

Dr Guy Rowlands, the editor-in-chief of the St Andrews Studies in French History and Culture, had the idea of developing a publication format shorter than a traditional research monograph back in 1998. He felt that this would fulfil a need in his discipline, but he was also determined that despite the shorter format the publications should be of exactly the same research quality as full-length research monographs. The idea took a further step forward when he got the inspiration for the name "midigraph" from his four-year-old son. ${ }^{3}$ In 2005 he took up his appointment in St Andrews as the first Director of the Centre for French History and Culture. Part of his remit was to launch a publication for the centre. Between 2005 and 2009 he faced the challenges of starting a publication from scratch, getting authors on board, finding a publisher, planning for distribution and marketing. By 2007 the essential idea for the format and scope of the publication series was well developed and it was time to approach publishers with the idea for a print publication. He

${ }^{3}$ At the time his four-year-old son was in the middle of a childhood obsession with small and large vans. The cross between a long and short van was soon described as a "midivan". Thus the idea of a the midigraph was born! 
approached two publishers. One, a large scale monograph publisher, could not see how the short monograph format would fit their existing publisher models and didn't buy into the concept. Another smaller publisher considered the idea, but required a substantial indemnity per publication of $£ 2-3,000$. This sort of financial investment broke the business model and was well in excess of the centre's annual budget. These setbacks in following traditional publishing routes were in fact the catalysts for a change in direction.

In the next couple of years the editor-in-chief and the newly formed editorial board became more aware of the ebook environment and much more familiar with digital delivery. They were naturally wary of "self-publication" but increasingly realised that digital delivery could be reputable and respected. Also, ebooks with rigorous peer review and quality layout could fulfil the needs of research communication and perhaps exceed the visibility the series might get if produced only in print and with a price tag. It was at this point that he made the connection with the university library. He realised that digital publication in-house, using institutional services and resources, could be a cost-effective and attractive solution.

A crucial element for success is quality peer review and editorial control. Much work has been done to develop and expand the editorial board across institutions and to bring particular experts on board on an ad hoc basis for individual titles. The editorial board has grown since the first ebook in 2010 and continues to expand.

All costs are funded from the research centre budget which is around $£ 1,200-£ 3,000$ per annum to cover all activities. Costing per issue comes in at the low to mid hundreds, and this allows for the production of two books per year. Costs include some technical work on layout, printing and postage. Editorial work is not costed but is absorbed into academic and research time. The library absorbs minimal staff costs to deposit the electronic books into Research@StAndrews:FullText and does value-added work such as metadata. The analysis of costs and use of existing centralised library services would suggest that this is very good value for money for the small budget available.

Marketing and publicity is targeted to coincide with the launch of each new book. Flyers are sent to all UK university libraries and selected overseas libraries. Alerts and announcements are posted online to major humanities networks such as $\mathrm{H}$-France and $\mathrm{H}-\mathrm{Net}^{4}$ and are designed to reach the most relevant disciplinary audience of humanities researchers and French history and studies researchers. Posts are also made to other discussion forums and book-review sites, for example the Institute of Historical Research. ${ }^{5} \mathrm{~A}$ limited

\footnotetext{
${ }^{4}$ http://h-net.msu.edu/cgi-bin/logbrowse.pl?trx=vx\&list=H-Catholic\&month=1002\&week $=\mathrm{a} \& \mathrm{msg}=8 \mathrm{gIxfxcx} 2 \mathrm{CgqTNKTUxhHGQ}$

${ }^{5}$ http://www.history.ac.uk/news/2012-08-31/new-book-centre-french-history-and-cultureuniversity-st-andrews
} 
print run, maximum 75 copies, is provided for authors and contributors, UK copyright library deposit and selected international libraries. The distribution of print is also another means of publicity.

As an institution St Andrews is very supportive of school initiatives and supports the development of research centres. The decision-making and budgetary control for this particular centre is devolved through the head of school for history, and the development of specialist centres in turn develops a group of disciplinary research experts and a fertile environment for the publication of research. This encourages sustainability.

\section{The library and institutional perspective}

The development of repository and open-access services in St Andrews has been well documented already (Aucock 2009, Proven and Aucock 2011). A research repository was introduced in pilot phase in 2002, and from 2006 the primary focus was a full service to support the deposit of electronic research theses. Since 2010, and the implementation of a Publication and Research Current Research Information Service, there has been increasing emphasis on open access to research publications authored by researchers within the institution. Activity has increased with the introduction of open-access mandates from funders. More recently, the Higher Education Funding Council for England (HEFCE) consultation and new policy statement in April 2014 has brought open access to centre stage in preparation for the post-2014 Research Excellence Framework. ${ }^{6}$ Although monographs are excluded from the compliance requirements in this new policy, HEFCE has indicated a longer-term interest in understanding open-access monograph publishing by setting up an Expert Reference Group. ${ }^{7}$ This project, in partnership with the Arts and Humanities Research Council and the Economic and Social Science Research Council, was due to report late in 2014.

There is a growing acknowledgement of open-access publishing developments from university research managers. The university has voiced a commitment to making research outputs available to a wider audience, as announced in its Open Access Policy ${ }^{8}$, and states: "We encourage academic authors to consider open-access publication of monographs where possible."

The library open access and research publications team has worked hard to create a set of services and systems which can support open-access publication. A good example is the library journal hosting service using Open Journal Systems (OJS), which began in 2011 and to date hosts eight

\footnotetext{
${ }^{6}$ Policy for open access in the post-2014 Research Excellence Framework (HEFCE 2014/07) http://www.hefce.ac.uk/whatwedo/rsrch/rinfrastruct/oa/policy

7 http://www.hefce.ac.uk/whatwedo/rsrch/rinfrastruct/oa/monographs

8 http://www.st-andrews.ac.uk/library/services/researchsupport/openaccess/oapolicy
} 
open-access journals..$^{9}$ The take-up of the journal hosting service has been primarily from humanities and social sciences disciplines, and has proved to be a useful exemplar of open-access publishing in precisely those disciplines where monographs are a primary vehicle of scholarly communication. This has sparked interest amongst researchers in these disciplines, and the services offer up the potential to become transferable to the monograph publishing environment.

Repository content has built up to a critical mass of quality full-text content, making it an attractive option for depositing and archiving full text in an institutional setting. Much work has centred on increasing awareness of open access and communicating the changing landscape of scholarly communication. It has concentrated on building relationships with academic schools, research groups and individual researchers, and engaging in dialogue with researchers to improve research support services. This in turn has created an environment which facilitates collaboration.

Rewards have come by steady progress in embedding our services within the research community of the university and being known to be open and receptive to new ideas and initiatives. So when the editor-in-chief had his first conversation with library staff he already expected that the library would play a supportive role and would engage with the publication process. The solution of using the institutional repository to host an ebook series has simplicity, but the library was able from the outset to offer robust and real services which give added value and essential infrastructure to support publishing initiatives.

The library provides a DSpace institutional repository as an established platform for hosting with underlying technical and development support from the Scottish Digital Library Consortium (SDLC). User support is provided by the open access and research publications team and deposit is mediated by the library on behalf of the ebook editorial team. The repository platform provides good discovery and visibility as well as centralised and secure archiving (multiple format versions of the ebooks in PDF and RTF are stored centrally). The repository also provides usage statistics for page views and downloads. Discovery and visibility are further enhanced by the creation of good quality metadata for each publication. Metadata is created using the Dublin Core schema and includes abstract, keywords, full headings for authors and editors, series headings and subject headings and classification using Library of Congress schema. Very similar detailed metadata is created in Machine Readable Cataloguing (MARC) format for the St Andrews library catalogue and both the Dublin Core records and the MARC records for the e-books are then made available for discovery and reuse in other databases and discovery systems. Metadata is harvested and made available in established services

\footnotetext{
9 http://ojs.st-andrews.ac.uk
} 
such as OAIster ${ }^{10}$, WorldCat ${ }^{11}, \mathrm{COPAC}^{12}$ and other aggregator sites such as BASE $^{13}$ and CORE. ${ }^{14}$

\section{The author perspective}

The digital and open-access aspects of these books have not been perceived at all as inhibitors to their potential authors. Authors fully support the model and see this as an accepted way to publish. The shorter format may take some adjustment for authors used to publishing at article or full monograph length, but it can also fit well around collected essays and conference-length pieces and so can prove to be versatile and fulfil a need. A positive example of these publications being endorsed centred on a discussion about inclusion for a tenure portfolio for an academic author in the USA, where key benefits were visibility and access and the very real advantages of being read.

Authors have favourably compared their experience to the traditional print route, describing how their first monographs were expensive to purchase and royalties were small, even though print runs did sell out. Authors want to be read, so an open-access digital approach has high value. They also comment that a quality editorial board, high production values and rigorous peer review are also vital when migrating publication to a non-traditional format. There is now greater acceptance that online and high quality can go hand in hand. When academics publish in an ebook series such as this they are adding momentum to this acceptance process and endorsing it themselves. These ebooks can still be reviewed in specialist journals by peers and experts in just the same way as print books.

Immediate accessibility is seen as a distinct advantage. It can usefully be tied in with online publicity using blogs and author video interviews, and the reader can literally be anywhere in the world with suitable network access to follow the link instantly to read or download the digital copy. Readers don't have to wait for print copies to be ordered for their library at a cost. Academics, including the authors themselves, can easily recommend the material instantly for reading lists and assignments. The format is ready-made for online teaching, where it can be fully integrated as digital material in the course structure. Because the material is already in a good quality digital format, does not need to be scanned, and is already copyright cleared, then it can very quickly and conveniently be used for teaching without the extra burden of administrative overheads. The ebooks are open to the general public and to

\footnotetext{
10 http://oaister.worldcat.org

11 http://www.worldcat.org

12 http://copac.ac.uk

13 http://www.base-search.net

14 http://core.kmi.open.ac.uk/search
} 
groups such as future students so they help to bridge the gap from scholarship to more general readership, as well as potentially influencing student recruitment and research collaboration.

Authors in the humanities understand and accept that traditional publishers and university presses still have a vital role, and that publishers who move to digital publication may still operate in a profit-making model. However, a specialised research centre can offer advantages over this model. A research centre is often much better placed to commission quality peer review than a traditional publisher. The elimination of any profit motive in publication can also give the editorial board and authors much more control and freedom in their publishing schedule and the choice of manuscripts.

\section{Usage, reach and value}

There are many and varied aspects to the usage, reach and value of these publications, some quantitative and some qualitative, and in both cases perhaps not always easy to measure and benchmark. What follows gives some indicators of the impact and visibility of these ebooks in the early stages of their open-access life.

Research@StAndrews:FullText ${ }^{15}$ offers download and page view statistics on its content, based on data gathered by Google Analytics. Usage statistics on the ebook series are available for the collection as a whole and for individual ebooks, and can be aggregated over varying time periods. Figure 2 shows downloads for all six titles in the series, and the current download total up to April 2014 is 1239 downloads, giving an average of over 200 downloads per title. Figure 3 shows statistics for the latest book in the series, launched in September 2013, which already has figures of over 100 downloads in its relatively short existence. These statistics show healthy usage which compares favourably with the standard print runs and sales of traditional print monograph publications, quoted recently in the OAPEN-UK Project Plan, which notes that these have declined to "little more than 200 in the early years of this century". ${ }^{16}$

Analysis of the geographical origin of traffic to the set of publications indicates the UK, the USA and France as the top three sources. Drilling down to traffic from city level gives some interesting correlations with the subject matter of the books. Top city traffic comes from St Andrews and London, but in the next rank is Paris and then Blois. This would seem to indicate that there is potential direct interest to material related to the history of Blois coming directly from that location and facilitated by digital delivery of the content.

\footnotetext{
${ }^{15}$ http://research-repository.st-andrews.ac.uk/gastatistics/collection?handle=10023\%2F84 6\&submit_simple=View+Statistics

${ }^{16}$ http://oapen-uk.jiscebooks.org/overview/project-plan
} 


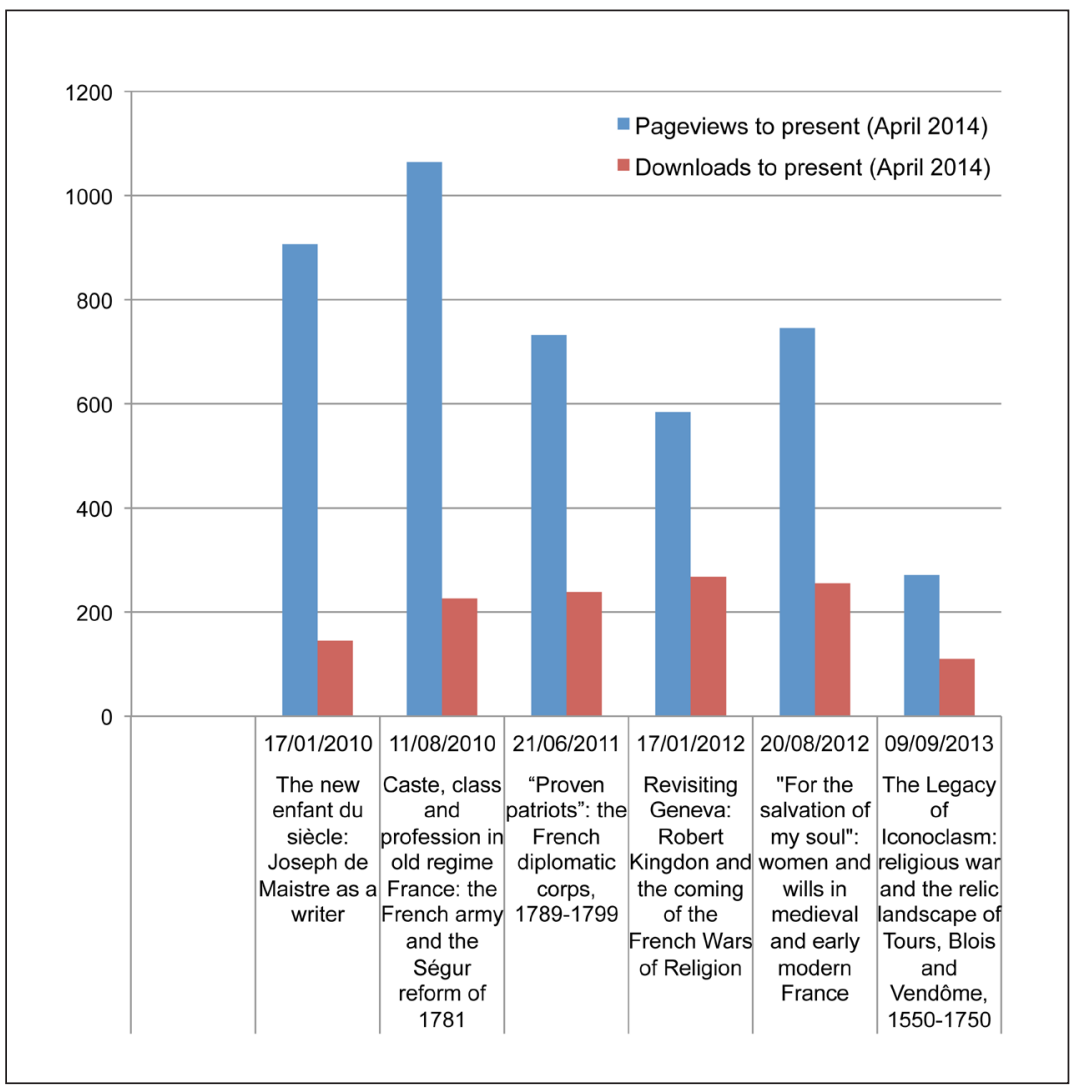

Figure 2: E-book series showing load date, title, page views and total downloads to April 2014.

Research@StAndrews:FullText as a whole received some 130,000 downloads from the site during the four years that these ebooks have been available, with monthly download figures now increasing to a steady average of 5,000 per month. Hits and page views on the site now average at more than 30,000 per month and the yearly increase of hits over the period shows a trend of steady upward growth. Just over $75 \%$ of these hits came from Google and Google Scholar, and the analytics for the geographical origin of traffic to the repository clearly show a global audience. The repository platform facilitates ease of digital discovery and delivery, especially because of its proven ability to provide good metadata content to search engines. An increasing amount of traffic is being driven to the site and this in turn has benefited the global visibility of specialist content such as the ebook series.

There are other facets to the reach and value of these publications. The series, and in particular its open-access ebook publication format, was 


\begin{tabular}{|c|c|}
\hline \multicolumn{2}{|c|}{ No. of Page views } \\
\hline Year/Mo & Page view: \\
\hline 2013/08 & 0 \\
\hline 2013/09 & 92 \\
\hline $2013 / 10$ & 43 \\
\hline 2013/11 & 24 \\
\hline 2013/12 & 17 \\
\hline 2014/01 & 29 \\
\hline 2014/02 & 12 \\
\hline 2014/03 & 30 \\
\hline 2014/04 & 44 \\
\hline 2014/05 & 28 \\
\hline 2014/06 & 13 \\
\hline 2014/07 & 12 \\
\hline 2014/08 & 4 \\
\hline Total & 348 \\
\hline
\end{tabular}

No. of Downloads
\begin{tabular}{|ll|}
\hline Year/Month Downloads \\
$2013 / 08$ & 0 \\
$2013 / 09$ & 40 \\
$2013 / 10$ & 17 \\
$2013 / 11$ & 8 \\
$2013 / 12$ & 8 \\
$2014 / 01$ & 15 \\
$2014 / 02$ & 2 \\
$2014 / 03$ & 10 \\
$2014 / 04$ & 15 \\
$2014 / 05$ & 11 \\
$2014 / 06$ & 4 \\
$2014 / 07$ & 4 \\
$2014 / 08$ & 2 \\
Total & $\mathbf{1 3 6}$ \\
\hline
\end{tabular}
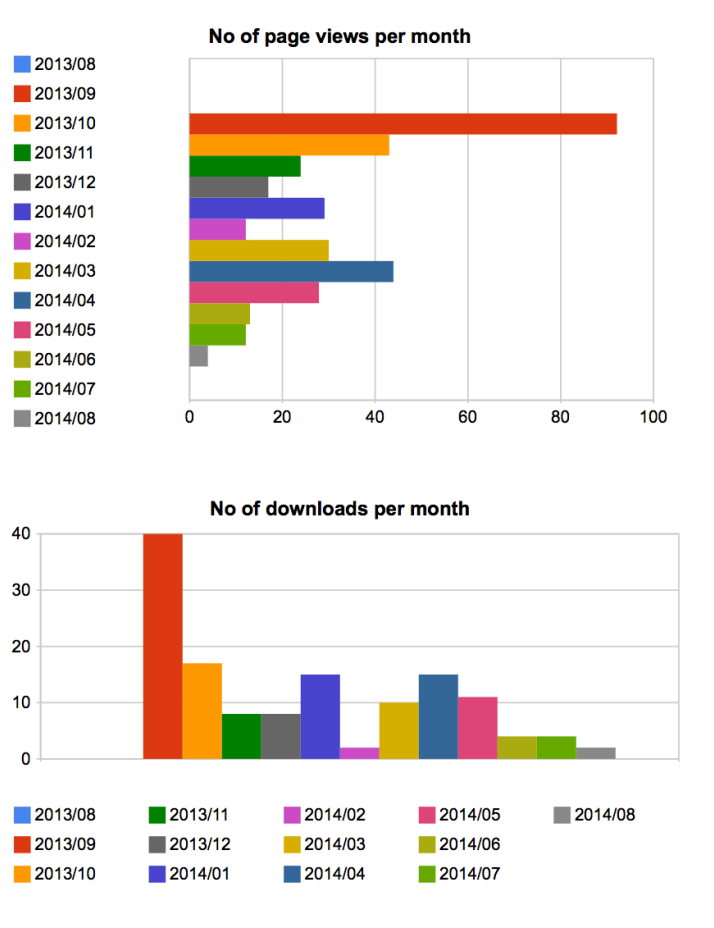

Figure 3: NELSON, E. (2013). The legacy of iconoclasm: religious war and the relic landscape of Tours, Blois and Vendôme, 1550-1750. http://hdl.handle.net/10023/4038 Page views and downloads since the book launch in September 2013.

specifically referenced and used as part of the evidence for research assessment in the School of History environment statement for the 2014 Research Excellence Framework (REF) assessment exercise. Environment statements count for $15 \%$ of the REF assessment and are assessed in terms of "vitality and sustainability". ${ }^{17}$ This was in the context of the value of the St Andrews Centre for French History and Culture as an intellectual and social focus for staff and postgraduate students and as an exemplar of how the centre forges strong international links.

In the "author perspective" section, I gave strong indications of the value of this publication format for immediacy of access and teaching and for ease of reuse. Some examples of this are a publication being listed on a syllabus list at the University of California Santa Barbara for a course in Urban Space in Late

${ }^{17}$ http://www.ref.ac.uk/panels/assessmentcriteriaandleveldefinitions 
Medieval and Early Modern Europe ${ }^{18}$, and a subject guide at the University of Reading providing access to free internet resources for French studies, specifically referencing the ebook series. ${ }^{19}$ The editor and centre have expressly stated that they want other libraries to make digital copies and provide links. The count of traffic coming in at city level from Exeter points to the links with the Centre for Early Modern Studies at the University of Exeter, where one of the publications' authors is based ${ }^{20}$, and the inclusion of the records for the digital ebooks in the University of Exeter's library catalogue. The catalogue provides direct URL links and describes the books as being freely accessible at St Andrews, thus immediately promoting discovery and usage. At Cornell University one publication has been copied and included in their repository eCommons@Cornell monographs collection. ${ }^{21}$ All these examples point to the development of a discipline-based open community of reuse around the ebooks.

There is clearly value to the research institute itself. It gains visibility and opportunities for collaboration by promoting its expertise and value through accessible quality publications. The value of the research institute is demonstrated and reinforced within the institution, and the academic institution in turn gets the same benefits.

At the level of personal and professional development, the editor of these publications develops an enhanced skill set as part of the process, such as aesthetic design, layout of publications and desktop publishing knowledge. In the longer term these may be skills that sit better with a centralised publication service, but in the short term they are highly beneficial skills to acquire and understand, and serve to better inform academic researchers about all aspects of the publication process, including business and costing models for open-access monographs.

From the library perspective what better way to demonstrate the effectiveness of open-access publication support services than by collaborating on a successful set of ebook publications? The library uses this series as an exemplar when giving support sessions to academic researchers and postgraduate students, and to raise open-access awareness. The existence of these ebooks can help to develop a dialogue, especially with other humanities researchers, and helps the library to understand the types of research support it needs to provide.

${ }_{18}$ http://www.google.co.uk/url?sa=t\&rct=j\&q=\&esrc=s\&source=web\&cd=24\&ved=0CDoQ FjADOBQ\&url=http\%3A\%2F\%2Fwww.history.ucsb.edu\%2Fcourses\%2Ftempdownload. php\%3Fattach_id\%3D6286\&ei=nIROU-_VJ8vFPZqegaAB\&usg=AFQjCNHdFPOp1zYSLYE5 604fNH_bR_ya3Q\&bvm=bv.64764171,d.ZWU\&cad=rja

${ }_{19}$ http://www.reading.ac.uk/library/finding-info/subjects/french/lib-french-internet. aspx

${ }^{20}$ http://humanities.exeter.ac.uk/history/research/centres/earlymodern

${ }^{21}$ http://ecommons.library.cornell.edu/handle/1813/31546 


\section{The future}

There are some practical aspects to the future development of these publications. The repository platform is functional, but there are plans to enhance it with a more professional look and feel, and to introduce extra publication formats to support more varied reading devices. Detailed licensing for the ebooks still needs to be finalised, and they can then be registered for the Directory of Open Access Books.

Within the university there is a growing buzz of interest and awareness of open-access and digital publication. Not yet a torrent, but rather a bubbling under of people talking and debating and watching the activities of their colleagues in this area and wondering if they should be considering similar initiatives. A series of ebooks may not of itself move the debate along, but as an exemplar of open access in practice, combined with many other drivers and influences, it can potentially change the scholarly communication culture in an institution or within a disciplinary area. The library has noticed a steady upturn in institutional requests to host new open-access journals on its hosting platform.

Another current debate in the university and an agenda item at library and academic strategic meetings is the question of setting up a University Press, which would include the publication of monographs and is very much in line with recent activities in other institutions such as University College London. ${ }^{22}$ This might in particular offer opportunities for new researchers and young academics, for example to publish research theses selectively. The recently published "Policy for open access in the post-2014 Research Excellence Framework (HEFCE 2014/07)", also now hotly debated within the university, offers another potent driver for open-access monographs when it states that "Where a higher education institution can demonstrate that it has taken steps towards enabling open access for outputs outside the scope of this definition (currently journal articles and some conference proceedings), credit will be given in the research environment component of the post-2014 REF".

Meanwhile, the relative simplicity of the publication process for the St Andrews Studies in French History and Culture continues to promote sustainability and continuity. The next volume is in preparation and is a very topical publication on French civilians in World War One. It will be made available online and promoted following a well-established procedure. In addition it will almost certainly become part of collaboration with the library's own series of events commemorating 1914-1918 and another example of research centre and library partnership in action.

\footnotetext{
22 http://www.ucl.ac.uk/library/ucl-press
} 


\section{Acknowledgement}

I am indebted to the editor-in chief of the series Dr Guy Rowlands for his valuable contribution to this study and to Dr Eric W. Nelson, Professor in the History Department of Missouri University, for his extremely helpful insights into his experiences as an author of one of the books.

\section{References}

Aucock, J. (2009) Developing the Digital Research Repository at the University of St Andrews, SCONUL Focus, 46. http://hdl.handle.net/10023/4584 Proven, J. and Aucock, J. (2011) Increasing uptake at St Andrews: Strategies for developing the research repository, ALISS Quarterly, 6(3): pp. 6-9. http://hdl.handle.net/10023/1824 